\title{
Role And Outcomes of Conservative Treatment in Management of Rotator Cuff Tears: A Systematic Review of Randomised Controlled Trials
}

\author{
Andrew Arjun Sayampanathan ${ }^{1}$, Marcus Wei Ping Tan ${ }^{2}$, Denny Tjiauw Tjoen Lie $^{2}$
}

\section{Abstract}

Rotator cuff tears are known to result in significant societal burden. This review synthesises the evidence regarding the role and outcomes of conservatively managed rotator cuff tears. 17 prospective randomised controlled trials (RCTs) (Level 1 and 2 studies) were included in this systematic review. Modalities which were studied were classified into physical rehabilitative modalities, electrophysiological rehabilitative modalities, biological therapies, and pharmacologic therapies. Outcomes which were evaluated in the included RCTs comprised of clinical outcomes, functional outcomes, pain scores, quality of life scores, imaging based outcomes, and patient satisfaction scores. As the modalities and outcomes studied were varied, no quantitative analysis could be performed based on the primary data available. Nevertheless, most studies do suggest that conservative treatment remains beneficial for the management of rotator cuff tears. Based on these findings, an algorithm which proposes conservative therapy as the central mode of management for rotator cuff tear patients has been described. More high-quality studies are required in this area of study to allow for a quantitative review (meta-analysis and meta-regression) of the various non-surgical treatment modalities of rotator cuff tears.

Keywords: Rotator CuffTears; Conservative; Non-operative; Management; Randomised controlled trials; Review.

\section{Introduction}

Rotator cuff tears are one of the most common shoulder disorders treated by orthopaedic surgeons, responsible in up to $85 \%$ of patients who present with shoulder pain [1]. Primarily a degenerative condition, it has a reported prevalence of around $10 \%$ in patients aged 50 to 59 years old, increasing to up to $80 \%$ in patients 80 and older [2-4]. Of these patients, up to two-thirds become symptomatic [2], resulting in pain and functional limitation. Moreover, unlike other degenerative conditions that predominantly affect older patients, societal burden of rotator cuff tears are significant, since more than twothirds of such patients present during working age [5], especially in manuallabourers [6].

Rotator cuff tears have a wide spectrum of severity, ranging from partial thickness tears of a single tendon to massive tears of two or more elements of the rotator cuff which can be treated operatively or nonoperatively $[7,8]$. While surgical repair is widely accepted as the standard of care for acute or acute-on-chronic traumatic tears $[9,10]$, the management of chronic tears remains controversial [11]. Proponents of surgical repair in these patients have often cited benefits of a reduced risk of tear progression [12], reduced cost burden and recovery time [5] and with improvements that persist in the long-term [13]. However, unlike acute tears, chronic tears usually lead to fatty infiltration and rotator cuffatrophy, which have been found to be poorly amenable to surgical repair and lead to poorer outcomes $[14,15]$. Conversely, nonoperative therapies, primarily involving physical therapy and nonsteroidal anti-inflammatory drugs (NSAIDs), have been found to be effective in up to $75 \%$ of patients [16]. Systematic reviews evaluating outcomes between operative and nonoperative treatment have generally revealed mixed results, with some reviews failing to demonstrate a clear benefit to surgery $[7,17]$, while others have suggested surgery may be more effective than conservative treatment $[18,19]$ with a caveat of insufficient evidence.

Hence, the current literature recommends for rotator cuff tears to be managed with analgesia and physical therapy for a period before considering surgery. Despite increasing rates of shoulder surgery [20], less than 1 in 4 patients with rotator cuff tears eventually elect to undergo surgery [16]. Consequently, there is a need for effective adjuncts to physical therapy alone, especially for patients who are precluded from surgery due to personal, cost, or medical reasons. Recently, advances in technology in non-invasive therapies, such as the use of biologic therapies [21] and electrophysiological rehabilitation, have provided a greater diversity of nonsurgical options to patients.

This aim of this article is to summarize the various nonoperative modalities that can be offered to patients with atraumatic rotator cuff tears, and to evaluate how they compare with operative management.

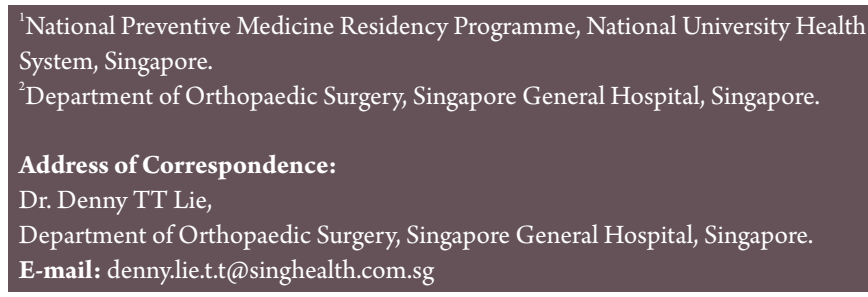

Submitted: 05 April 2021; Reviewed: 28 April 2021; Accepted: 10 May 2021; Published: 10 June 2021

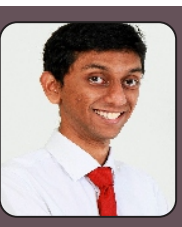

Dr. Andrew Arjun Sayampanathan

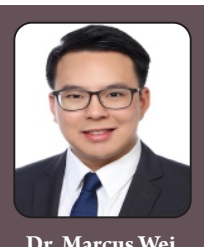

Dr. Marcus Wei Ping Tan

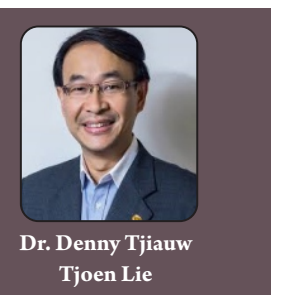

Asian Journal of Arthroscopy | ISSN 2456-1169| Available on www.asianarthroscopy.com | DOI:10.13107/aja.2021.v06i01.024|

This is an open access journal, and articles are distributed under the terms of the Creative Commons Attribution Non-Commercial-Share Alike 4.0 License (http://creativecommons.org/licenses/by-nc-sa/4.0) which allows others to remix, tweak, and build upon the work non-commercially as long as appropriate credit is given and the new creation are licensed under the identical terms. 


\section{Methodology}

A systematic review was performed, identifying articles from PubMed and Embase. The following MeSH term was used to identify titles, abstracts and keywords relevant to the review: 'rotator cuff' AND ('treatment' OR 'therapy' OR 'management') AND 'trial'. Only articles from $1^{\text {st }}$ January 2010 till the date of search (15 th August 2020) were included.

All articles studying the outcomes of conservatively managed rotator cuff tears in the form of a prospective randomised controlled trial (RCT) were included in this review. Studies which were not related to this topic, not published in English, included other rotator cuff lesions in the analysis other than rotator cuff tears, or had no discussion on conservative treatment for rotator cuff tears were excluded from the study. Review articles, case reports, non-RCTs, basic science studies, animal studies and cadaveric studies were also excluded from this review. The elimination of studies were performed in a systematic fashion by a single author. The characteristics and findings from included studies were synthesised thereafter in the form of tables.

\section{Results}

A total of 1172 articles were identified from the databases. After the removal of 259 duplicates, 913 articles remained for screening and elimination based on the exclusion criteria described above. 816 articles were eliminated based on the screening of titles. A further 70 articles were removed based on the screening of abstracts. After screening of full texts, 17 prospective randomised controlled trials were included within this review [22-37]. A summary of the elimination process can be found in Figure 1. The cumulative outcome of 1117 shoulders were included in the review.

Out of the 17 studies, 4 studies only included patients with full thickness rotator cuff tears. 4 studies focused on comparing the outcomes of conservatively managed and surgically managed rotator cuff tears revealing inconclusive results overall. Other studies compared the outcomes of various modalities, which can be classified into physical rehabilitative modalities (physiotherapy, occupational therapy and home based therapy), electrophysiological rehabilitative modalities (eg. Transcutaneous Electrical Nerve Stimulation (TENS) and Microcurrent Electrical Nerve Stimulation (MENS)), biologic therapies (PRP, BMAC and corticosteroids) and pharmacologic therapies (eg. injectable corticosteroids). A summary of study

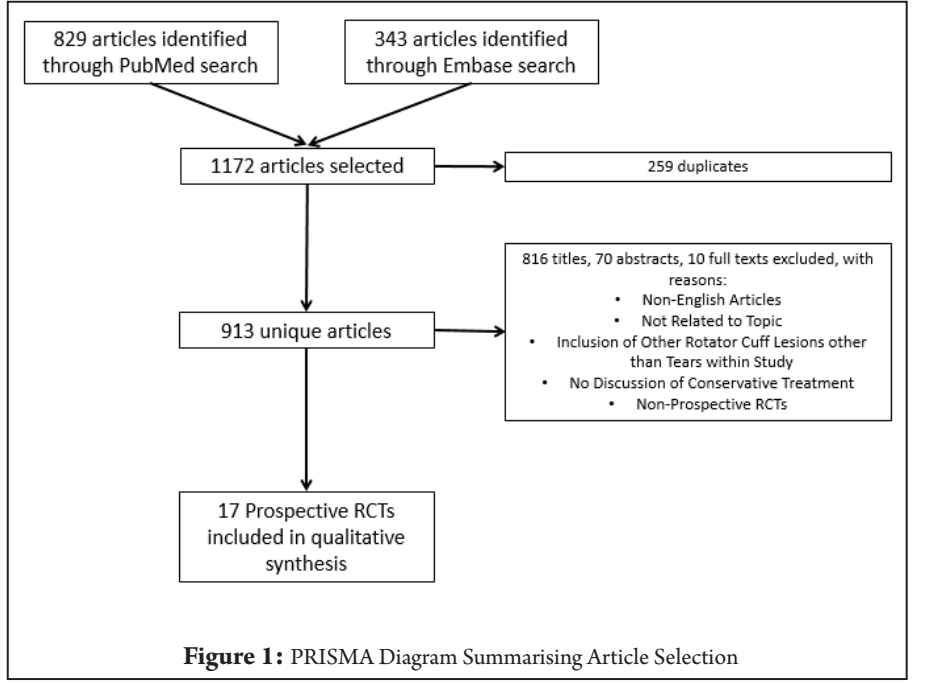

characteristics and modalities studied can be found in Table 1. A variety of outcome variables were studies, mainly comprising of clinical outcomes (eg. active shoulder range of motion (ROM) and power), functional outcomes (eg. ASES, Constant and WORC scores), pain scores (eg. VSA score), quality of life scores (eg. SF-36 and EQ-5D scores), imaging based outcomes (utilising either ultrasound, MRI or MR arthrograms to assess tear recovery, progress and/or re-tear rates) as well as patient satisfaction scores. A summary of outcome variables assessed and study findings can be found in Table 2 .

\section{Discussion}

The spectrum of options for the non-surgical management of rotator cuff tears is wide. This systematic review has synthesised the evidence regarding non-surgical options studied in prospective randomised controlled trials. From these findings, we propose a treatment algorithm for rotator cuff tears, which we will describe below.

The majority of studies included within this review only studied partial rotator cuff tears. When surgical management was compared with nonsurgical management for partial rotator cuff tears, there were conflicting conclusions on the differences in outcomes of both groups. Kukkonen et al [35] and Ranebo et al [32] revealed that there was no significant difference in functional outcomes and pain scores in both groups. However, Moosmayer et al [33] revealed that at 10 years follow-up, there was a difference in functional outcomes and pain scores for patients who underwent primary tendon repair when compared to patients who underwent physiotherapy with optional secondary repair. When surgical management was compared to non-surgical management of full thickness rotator cuff tears, there was some evidence that functional outcomes were superior for the surgical group as well. This review thus suggests that surgical treatment can be considered for rotator cuff tears. However, non-surgical management should always be considered as the primary and initial modality of treatment for rotator cuff tears, especially partial tears. For partial rotator cuff tears, surgery should only be considered when there is evidence of failure of non-surgical treatment.

\section{Indications for non-surgical treatment}

Most, if not all, patients with suspected rotator cuff tears will receive a trial non-surgical treatment in the prelude to surgery, while the imaging is done to confirm the diagnosis. However, the conservative nonsurgical treatment remains a trial, and is not the definitive treatment. Are there patients in whom the definitive treatment of choice is nonsurgical? In our opinion, these patients can fall into one of these categories:

\section{Patients who are not keen on surgery}

Various reasons abound, patients may refuse surgery due to ignorance of the procedure, bias, fear and misunderstanding, and the costs of the surgery may be prohibitive.

\section{Patients who are not fit for surgery}

Patients requiring cuff surgery tend to be frail elderly individuals with pre-existing co-morbidities such as diabetes mellitus, ischemic heart disease and rheumatoid arthritis. Those who are ASA II and above and who are obese $(\mathrm{BMI}>35)$ are at risk. These effects might pose great challenges to the anesthetists in the conduct of anesthesia, airway management, and surgical positioning of patients. 


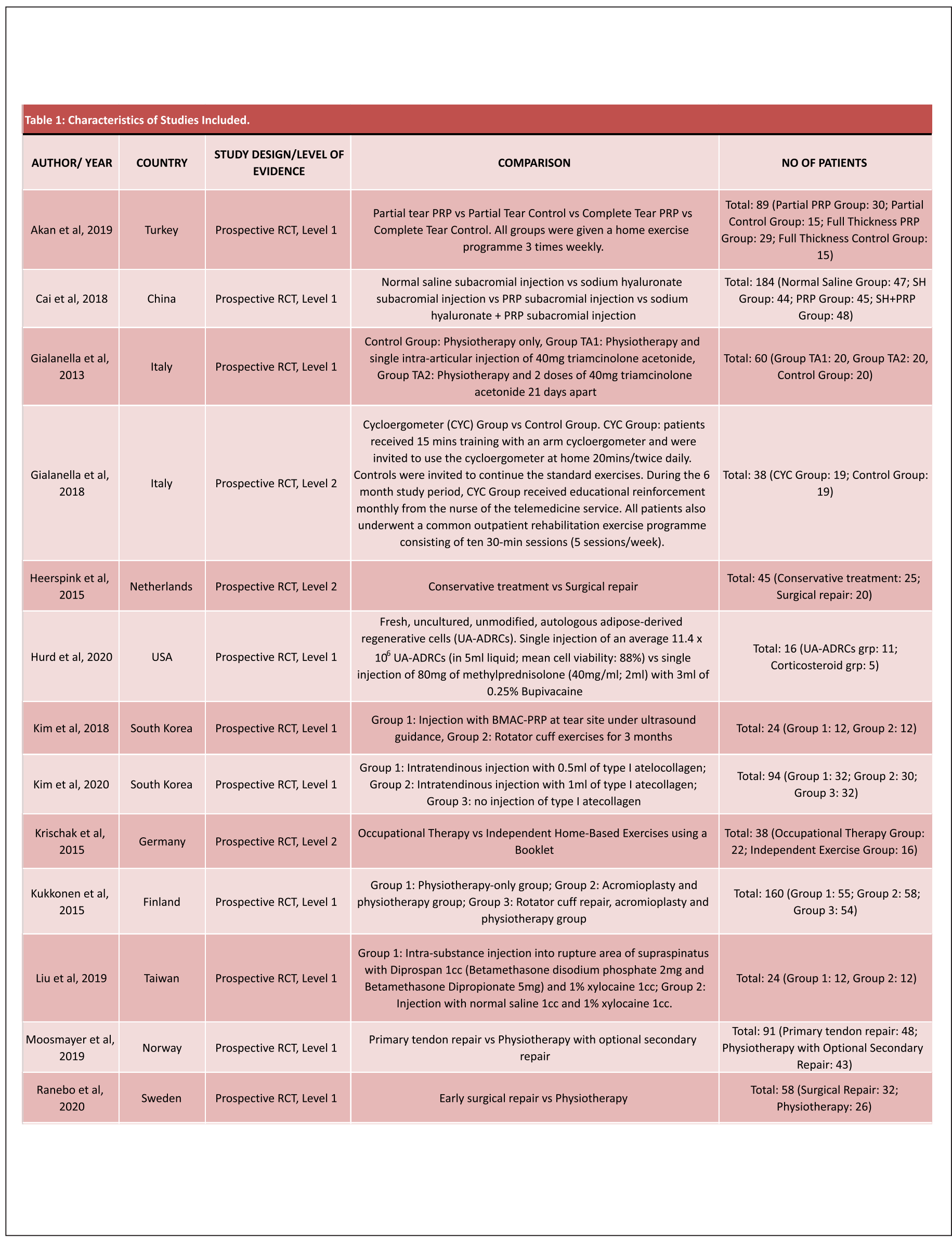




\begin{tabular}{|c|c|c|c|}
\hline $\begin{array}{l}\text { AUTHOR/ } \\
\text { YEAR }\end{array}$ & PARAMETERS STUDIED & $\begin{array}{l}\text { MINIMUM FOLLOW } \\
\text { UP (MONTHS) }\end{array}$ & SIGNIFICANT FINDINGS \\
\hline $\begin{array}{l}\text { Akan et al, } \\
2019\end{array}$ & $\begin{array}{l}\text { ROM, Quick DASH Score, SPADI Score, } \\
\text { Constant Score, VAS Score }\end{array}$ & 12 & $\begin{array}{l}\text { In all groups, statistically significant improvements were observed in ROM, Quick } \\
\text { DASH, SPADI, Constant and VAS scores at } 12 \text { months }(p<0.05) \text {. More improvements in } \\
\text { all these clinical parameters were observed in PRP groups than control groups } \\
(p<0.001) \text {. Improvements seen after their first injection in PRP groups had persisted } \\
\text { at } 12 \text { months. No significant difference in clinical parameter improvements between } \\
\text { PRP groups. }\end{array}$ \\
\hline $\begin{array}{l}\text { Cai et al, } \\
2018\end{array}$ & $\begin{array}{l}\text { Primary outcome: Constant score; } \\
\text { Secondary outcomes: ASES Score, VAS } \\
\text { Score, MRI }\end{array}$ & 12 & $\begin{array}{l}\text { PRP Group and SH+PRP Group showed significantly higher Constant and ASES scores } \\
\text { post-intervention. At } 12 \text { months, there were significant differences in Constant, VAS } \\
\text { and ASES scores between SH+PRP Group when compared to SH and PRP groups. Tear } \\
\text { size significantly decreased on MRI for both the PRP and SH+PRP groups. }\end{array}$ \\
\hline $\begin{array}{c}\text { Gialanella et } \\
\text { al, } 2013\end{array}$ & $\begin{array}{l}\text { ROM, Constant-Murley Scale, Pain } \\
\text { score, Requests for NSAIDs }\end{array}$ & 6 & $\begin{array}{c}\text { Groups TA1 and TA2 had less pain at night at } 6 \text { months }(p=0.023 \text { ), better improvement } \\
\text { in pain at night at } 6 \text { months ( } p<0.001) \text {, better effectiveness in pain at night at } 6 \\
\text { months ( } p<0.001) \text {, better improvement in pain during activity at } 6 \text { months }(p<0.001) \text {, } \\
\text { better effectiveness in pain during activity at } 6 \text { months ( } p<0.001)\end{array}$ \\
\hline $\begin{array}{c}\text { Gialanella et } \\
\text { al, } 2018\end{array}$ & $\begin{array}{l}\text { VAS Score, Active ROM, Passive ROM, } \\
\text { ROM-Pain, Revised Constant Score, } \\
\text { HAQ Score }\end{array}$ & 6 & $\begin{array}{l}\text { At } 6 \text { months, CYC Group showed significant improvement in all outcome measures } \\
(p<0.01) \text {; At } 6 \text { months, compared to Control Group, CYC Group had lower pain scores } \\
\text { during activities }(p<0.01) \text {, higher revised Constant total score }(p<0.01) \text {, better ROM- } \\
\text { pain }^{\text {sum }}(p<0.05) \text { and active ROM } \mathrm{M}^{\text {jum }}(p<0.05) \text {; At } 6 \text { months, home cycloergometer use } \\
\text { was inversely associated with pain during activities }(p<0.01) \text { and revised Constant } \\
\text { total score }(p<0.01)\end{array}$ \\
\hline $\begin{array}{c}\text { Heerspink et } \\
\text { al, } 2015\end{array}$ & $\begin{array}{c}\text { CMS Score, VAS Pain Score, VAS } \\
\text { Disability Score, MRI }\end{array}$ & 12 & $\begin{array}{l}\text { At } 12 \text { months, VAS pain and VAS disability scores were significantly lower in the } \\
\text { surgery group ( } p=0.04 \text { and } 0.02 \text { respectively). No difference in mean CMS score in } \\
\text { both groups at } 12 \text { months ( } p=0.08 \text { ). Subgroup analysis showed that postoperative CMS } \\
\text { results were superior in surgically treated patients without a retear compared with } \\
\text { conservatively treated patients. }\end{array}$ \\
\hline $\begin{array}{l}\text { Hurd et al, } \\
2020\end{array}$ & $\begin{array}{c}\text { ASES Score, RAND SF-36 Score, VAS } \\
\text { Score, MRI }\end{array}$ & 12 & Higher mean ASES score in UA-ADRCs group 52 weeks post injection $(p<0.05)$ \\
\hline $\begin{array}{c}\text { Kim et al, } \\
2018\end{array}$ & $\begin{array}{l}\text { VAS Score, MMT Score of SSP, ASES } \\
\text { Score, tear size }\end{array}$ & 3 & $\begin{array}{c}\text { At } 3 \text { months post-injection, Group } 1 \text { had superior improvement in VAS Score } \\
(p=0.039) \text {, ASES Score }(p=0.011) \text {. Decrease in tear size also noted for participants in } \\
\text { Group } 1\end{array}$ \\
\hline $\begin{array}{c}\text { Kim et al, } \\
2020\end{array}$ & $\begin{array}{l}\text { ASES Score, Constant Score, VAS } \\
\text { Score, active ROM, MRI (performed at } \\
\text { least } 6 \text { months after injection) }\end{array}$ & 12 (Mean: 24.7) & $\begin{array}{l}\text { The functional and pain scores in Groups } 1 \text { and } 2 \text { significantly improved at final follow- } \\
\text { up ( } p<0.05) \text {. No significant improvement was seen in functional or pain scores for } \\
\text { Group } 3(p>0.05) \text {. Groups } 1 \text { and } 2 \text { had significantly better functional scores compared } \\
\text { with Group } 3 \text { at final follow-up ( }<<0.05 \text { ). Group } 1 \text { ( } 28.1 \%, p=0.02 \text { ) and Group } 2(36.7 \% \text {, } \\
p=0.003 \text { ) had significantly higher proportion of patients with decreased size of tendon } \\
\text { tear on follow-up MRI when compared to Group } 3(6.3 \%) \text {. }\end{array}$ \\
\hline $\begin{array}{l}\text { Krischak et } \\
\text { al, } 2015\end{array}$ & $\begin{array}{l}\text { VAS Socre, CMS Score, Isokinetic } \\
\text { strength testing in abduction and } \\
\text { external rotation, functional } \\
\text { limitation, clinical shoulder tests, EQ- } \\
\text { 5D VAS }\end{array}$ & 2 & $\begin{array}{l}\text { A } 2 \text { months follow up, change in EQ-5D-VAS Score, abduction peak torque ( } 60 \text { degrees } \\
\text { per second) and abduction peak torque ( } 120 \text { degrees per second) were greater for } \\
\text { Independent Exercises Group ( } p=0.049,0.01,0.005 \text { respectively) }\end{array}$ \\
\hline $\begin{array}{c}\text { Kukkonen et } \\
\text { al, } 2015\end{array}$ & $\begin{array}{l}\text { Primary outcome: Constant Score; } \\
\text { Secondary outcomes: VAS Score, } \\
\text { Patient Satisfaction Score, Rotator } \\
\text { Cuff Integrity in a control imaging } \\
\text { investigation, cost of treatment }\end{array}$ & 24 & $\begin{array}{l}\text { At } 2 \text { years, there was no significant differences in mean change in Constant Score, } \\
\text { VAS Score, Patient Satisfaction Score between all } 3 \text { groups }(p=0.38, p=0.45, p=0.28 \\
\text { respectively). At } 2 \text { years, the mean saggital site of tear was significantly smaller in } \\
\text { Group } 3 \text { compared to Groups } 1 \text { and } 2 \text { ( } p<0.01 \text { ). Rotator cuff repair and acromioplasty } \\
\text { were significantly more expensive than physiotherapy only }(p<0.01 \text { ). }\end{array}$ \\
\hline $\begin{array}{l}\text { Liu et al, } \\
2019\end{array}$ & US Imaging, SPADI Score, VAS Score & 6 & $\begin{array}{l}\text { At } 6 \text { months, superior improvement in VAS and SPADI Scores in Group } 1 \text { than Group } 2 . \\
\text { Therapeutic effect lasted for at least } 6 \text { months in both groups. Size of SSP rupture was } \\
\text { not increased after injection in either group ( } p=0.066 \text { for Group 1, } p=0.073 \text { for Group } \\
\text { 2). }\end{array}$ \\
\hline $\begin{array}{c}\text { Moosmayer } \\
\text { et al, } 2019\end{array}$ & $\begin{array}{l}\text { Constant Score, ASES Score, VAS } \\
\text { Score, motion, strength, Patient } \\
\text { Satisfaction Score }\end{array}$ & 120 & $\begin{array}{l}\text { Post } 10 \text { years follow-up, primary tendon repair had superior outcomes compared to } \\
\text { physiotherapy with optional secondary repair (Better Constant Score }(p=0.002) \text {, ASES } \\
\text { Score }(p<0.001), 10 \mathrm{~cm} \text { Visual Analogue Scale for Pain }(p<0.001) \text {, pain-free abduction } \\
\qquad(p=0.007) \text {, pain-free flexion }(p=0.01)\end{array}$ \\
\hline $\begin{array}{c}\text { Ranebo et al, } \\
2020\end{array}$ & $\begin{array}{l}\text { Primary outcome: CMS Score; } \\
\text { Secondary outcomes: WORC Score, } \\
\text { NRS Score, EQ-VAS score, MRI to asess } \\
\text { retear rate, tear progression, fatty } \\
\text { infiltration, atrophy }\end{array}$ & 12 & $\begin{array}{c}\text { No difference in CMS Score }(p=0.68) \text {, WORC Score }(p=0.62) \text {, NRS Score and EQ-VAS } \\
\text { Score }(p=0.60) \text { at } 12 \text { months. Retear rates for repaired patients: } 6.5 \% \text {, physiotherapy } \\
\text { patients: } 29.2 \% \text {. }\end{array}$ \\
\hline $\begin{array}{l}\text { Schwitzgueb } \\
\text { el et al, } 2019\end{array}$ & $\begin{array}{l}\text { Primary outcome: change in lesion } \\
\quad \text { volume (calculated on MR } \\
\text { Arthrography) at } 7 \text { months; Secondary } \\
\text { outcomes: improvement in shoulder } \\
\text { pain and the Constant Score, ASES } \\
\text { Score SANE Score at }>12 \text { months }\end{array}$ & 12 & $\begin{array}{l}\text { At } 7 \text { months, no significant differences between PRP and control groups in change in } \\
\text { lesion size }(p=0.175) \text {, change in VAS ( } p=0.586) \text {, change in SANE Score }(p=0.650 \text { ), } \\
\text { change in Consant Score ( } p=0.596) \text {, change in ASES Score ( } p=0.655) \text {; At }>12 \text { months, no } \\
\text { significant differences between PRP and control groups in change in VAS ( } p=0.087 \text { ), } \\
\text { change in SANE Score ( } p=0.846 \text { ). At } 19.5+/-5.3 \text { months, the incidence of adverse } \\
\text { effects ( } p \text { ain }>48 \text { hours, frozen shoulder, extension of lesion) was significantly higher } \\
\text { in the PRP Group than the Control Group ( } 54 \% v 26 \% \text { respectively; } p=0.020 \text { ) }\end{array}$ \\
\hline $\begin{array}{c}\text { Shams et al, } \\
2016\end{array}$ & $\begin{array}{l}\text { ASES Score, CMS Score, SST Score, VAS } \\
\text { Score, MRI (findings graded on scale } \\
\text { of } 0-5 \text { ) }\end{array}$ & 6 & $\begin{array}{l}\text { Both injection groups showed statistically significantly better clinical outcomes over } \\
\text { time. Statistically significant difference between PRP Group and Corticosteroid Group } \\
12 \text { weeks after injection for VAS, ASES, CMS and SST Scores, favouring PRP Group. Non- } \\
\text { significant improvement in MRI findings for both groups. No difference in outcomes } \\
\text { for both groups at } 6 \text { months. }\end{array}$ \\
\hline $\begin{array}{c}\text { Turkmen et } \\
\text { al, } 2018\end{array}$ & $\begin{array}{l}\text { Active ROM, VAS Pain Score, DASH } \\
\text { Score, ASES Score, SF-36 Score, } \\
\text { Treatment Satisfaction Level }\end{array}$ & 1.5 & $\begin{array}{c}\text { Statistically significant improvement in active ROM ( } p=0.001 \text { in both groups) and } \\
\text { secondary outcomes ( } p<0.05 \text { in both groups); no statistically significant difference in } \\
\text { all outcome measures between groups ( } p>0.05 \text { ) }\end{array}$ \\
\hline \begin{tabular}{|c|} 
Vrouva et al, \\
2019 \\
\end{tabular} & SPADI Score, NRS Score, EQ-5D & 3 & $\begin{array}{l}\text { Significant improvement in pain scores, functionality and patients' quality of life } \\
(p<0.001) \text {; no significant difference in treatment methods }(p>0.05)\end{array}$ \\
\hline
\end{tabular}




\section{Patients who may not need surgery}

These include those with partial thickness tears, and full thickness tears less than $10 \mathrm{~mm}$ in largest dimension. In our institution, these patients are treated conservatively first. They are usually handicapped mainly by pain and stiffness, both of which are amenable to physiotherapy. Outcomes with and without repair of such partial tears with stiffness are noted to be similar [38].

\section{Patients whose surgery may be delayed}

These are usually small to mid-sized full thickness tears which are wellbalanced (Figure 2), often described as U-shaped. These patients tend to be relatively asymptomatic or tolerate the symptoms well when the tear is small, and hence present late with pain and weakness when the tear has become large or massive. In contrast, unbalanced or asymmetrical tears, often described as L-shaped or reverse L-shaped may present early with pain. These patients need surgery without delay. Patients with balanced tears can be treated with conservative treatment, albeit on a trial. In our survey of 38 patients with large tears [39], it was found that up to $24 \%$ had balanced tears and indeed, presented late after a long period of conservative treatment.

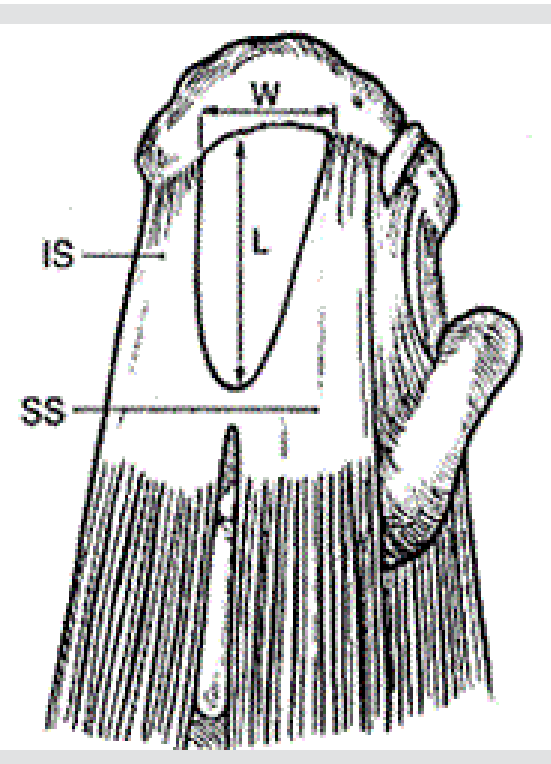

Figure 2: A balanced tear is one which involves largely the supraspinatus tendon with minimal or no tear noted in the subscapularis and infraspinatus.

\section{Nonoperative treatment modalities}

\section{Pharmacological therapy}

Analgesic medications, such as paracetamol (acetaminophen) and NSAIDs are commonly prescribed to patients with painful rotator cuff syndromes. By blocking the inflammatory process, NSAIDs are thought to reduce pain and inflammation at the rotator cuff tear site. The excellent short-term effectiveness of NSAIDs in the management of rotator cuff syndromes has been well described in the literature [40, 41]. However, the gastrointestinal, cardiovascular, and renal adverse effects preclude long-term use for patients who have chronic pain. Furthermore, there has been debate on the role NSAIDs play in inhibiting rotator cuff healing. Studies in rats have demonstrated that NSAIDs result in impaired rotator cuff tendon [42] and tendon-tobone [43] healing. However, the clinical impact of these inhibitory effects are less clear, with some reporting worse outcomes [15].
However, these studies investigate tendon healing after rotator cuff repair, while there is a paucity of evidence on the effect of NSAIDs on chronic rotator cuff tears. Hence, we commonly recommend NSAIDs for patients who have acute or acute-on-chronic flares of pain, while advising against long term NSAID use due to its side effect profile and potential adverse effects on tendon healing.

In patients with intractable acute pain not amenable to oral NSAID or paracetamol use, short course fixed dose opioid medications may be an option. However, its use should remain judicious, especially concerning its risks of respiratory depression and misuse.

\section{Physical therapy}

The main goal of physical therapy is to reduce pain and improve function via restoration of range of motion (ROM), shoulder strength, stability, and control. There are three distinct modalities, namely activity modification, stretching of the glenohumeral joint capsule and strengthening of the rotator cuff, scapular stabilizers, and deltoid muscles.

Firstly, patients should be educated to limit aggravating activities, such as overhead or reaching actions, to prevent further injury and pain. Next, patients should be placed on a comprehensive exercise and stretching program, with both physiotherapist lead sessions and home exercise program showing good results compared with placebo [44]. Patients can be initially started on passive pendulum exercises and progressed to active-assisted exercises using the other arm or a wall as tolerated. Special attention should be placed on anterior and posterior capsule stretching, to prevent adhesions and decrease impingement [45]. Targeted strengthening of the healthy rotator cuff muscles and scapular stabilizers should be performed in a progressive manner. The use of various adjuncts, such as elastic bands and weights, have been described [46] but individual specifics are beyond the scope of this review. Strengthening of these muscles helps in improving the stability of the glenohumeral joint and preventing superior migration of the humeral head and subsequent impingement [46].

While physical therapy is an essential component to the rehabilitative treatment for rotator cuff tears, to date there have been no randomized clinical trials that have evaluated its effectiveness. The ubiquity of physical therapy for patients with rotator cuff tears makes conducting such trials difficult. Goldberg et al [47] evaluated exercise therapy alone in an observational series of 46 patients with full thickness tears. The authors found that 27 patients (59\%) of patients experienced improvement, 5 (11\%) remained unchanged, while 14 (30\%) of patients experienced worsening at a mean follow up of 2.5 years. Kukkonen et al [35] evaluated patients with non-traumatic rotator cuff tears at 1 year, who underwent (1) physical therapy alone, (2) physical therapy and acromioplasty, and (3) physical therapy, acromioplasty and rotator cuff repair, and found no clinical differences between all groups at 1 year. A systematic review on exercise therapy in the treatment of rotator cuff impingement found that exercise is generally an effective treatment for pain reduction [48], although the results between each study are not comparable due to the heterogeneity of the various exercise programs reported. However, despite consensus that physical therapy is beneficial, there has been some evidence that patients who remain symptomatic despite therapy continue to undergo anatomic deterioration, as compared to patients who remain asymptomatic [49]. Hence, in such patients, surgery should be considered before fatty degeneration and muscle atrophy worsen. 


\section{Injections}

Corticosteroid injections into the subacromial space have been shown to provide effective short-term relief of pain resulting from rotator cuff tears $[7,19,45,50-52]$. Corticosteroids are commonly injected with a local anesthetic agent, such as lidocaine, to provide rapid pain relief, allowing patients to engage in physical therapy. By reducing the inflammatory process, corticosteroids are effective against acute tendinopathies and tears [45]. A systematic review on the effectiveness of such injections showed improved ROM of between 14 to 45 degrees, with most studies demonstrating statistically but not clinically significant improvements in the visual analog score for pain [53]. Such benefits were seen in patients regardless of the use of ultrasound guidance or anatomical approach. Regarding the longevity of pain relief, studies $[52,54]$ have reported that while there was effective pain relief at 1 month, such benefits were not seen at 3 months. Hence, given its short term effectiveness and recent concerns regarding corticosteroid mediated tendon necrosis [55], we recommend such injections to be given for a reduction of acute inflammation and resulting pain relief, in order for patients to embark on a course of physical therapy. We do not advise for repeat injections (e.g. more than once every sixth months) in view of its potentially detrimental effects on healthy tendons.

Recently, hyaluronic acid (HA) injections, while widely used for the treatment of osteoarthritis, have been gaining popularity in the treatment of tendinopathies such as rotator cuff tears. As a physiological component of synovial fluid, there has been some in vivo evidence on the efficacy of $\mathrm{HA}$ in treating tendinopathies. HA has been shown to suppress rotator cuff inflammation in a rat model [56], and reduced adhesions and improved tendon healing in Achilles tendon tears in a rabbits [57]. Whereas clinical evidence has been mixed, with some studies reporting improved pain and function [58], while others have reported inconclusive results [52]. In our view, more clinical trials are awaited before definite recommendations can be made on the use of HA for the treatment of rotator cuff tears.

\section{Biologic therapies}

Biologic therapies, such as the use of platelet-rich plasma (PRP), have been advocated for the treatment of tendinopathies. PRP contains a mixture of host growth factors, which has in vitro evidence of improved tendon healing and remodeling [59]. It is thought that delivery of high concentrations of growth factors to injured tendons can augment the healing process. Its efficacy has been a topic of debate, with some reviews reporting long-term clinical effectiveness [52], while other reviews has demonstrating no significant long-term improvements [21]. As presented in our results, Akan et al [29] found that PRP benefitted patients with both complete and partial tears, with improvements lasting at least 12 months. Conversely, Schwitzguebel et al [31] and Shams et al [30] reported that PRP injection did not improve lesion size, pain or functional outcomes at 6 and 12 months respectively. One possible reason for the heterogeneity of the results seen in the literature may be the high inter-individual variation in the composition of PRP [60]. Recently, there has been new evidence that injection of bone marrow mesenchymal stem cells with PRP can improve tendon regeneration, reduced pain and improve function [61], however this remains a topic for future study.

\section{Algorithm \\ The central role of conservative treatment of cuff tears is illustrated in the algorithm in Figure 3. Conservative treatment may be the definitive treatment in some patients, in those who are not keen or not fit for surgery. Conservative treatment has a role to play for those who may not need surgery, like patients with small tears. In those with mid-sized but balanced tears, conservative treatment may be part of the treatment cascade.}

\section{Limitations}

This review only includes prospective randomised controlled trials (level 1 and 2) which have studied at least 1 non-surgical modality for the treatment of rotator cuff tears. However, the treatment modalities

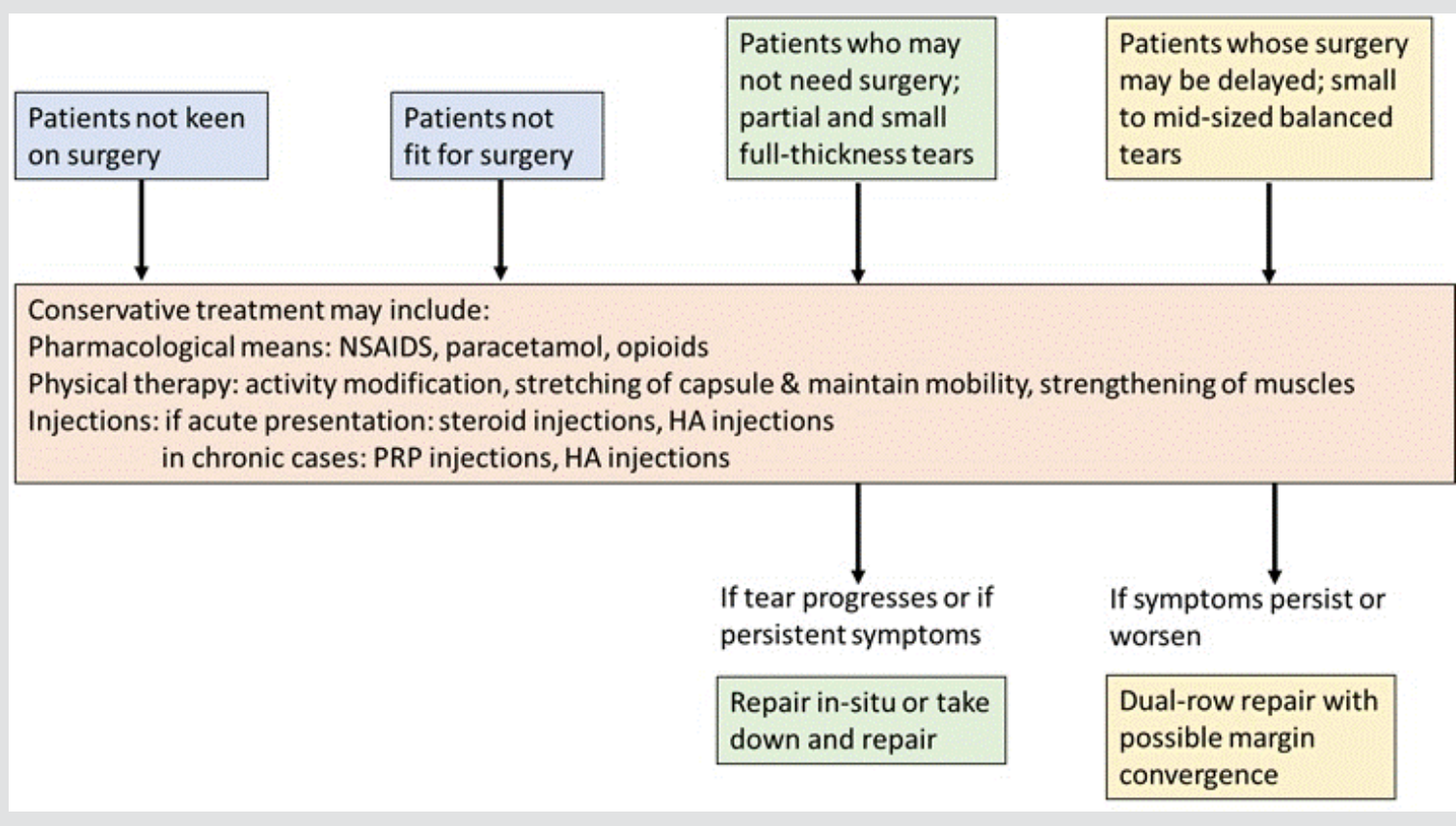

Figure 3: Algorithm to illustrate the role of conservative treatment in cuff tears 
available are extremely diverse, not allowing for a meaningful quantitative review of the topic. Furthermore, the way the treatment was delivered varied largely from study to study (for example dosages of pharmacologics and preparation techniques of biologics given via injections). The follow-up times varied between studies as well, ranging from 1.5 months to 10 years follow up. Moreover, expectedly, some of the studies were not able to blind participants and clinicians who provide the therapy for ethical reasons.

\section{Conclusion}

There are a variety of non-surgical modalities available for the treatment of rotator cuff tears. These can be classified into pharmacologic therapies, injections, biologics, physical rehabilitation, and electrophysiological rehabilitation modalities. These non-surgical modalities should be considered as first line treatment in the management of rotator cuff tears, especially partial tears. More highquality studies are required in this area of study to allow for a quantitative review (meta-analysis and meta-regression) of the various non-surgical treatment modalities of rotator cuff tears.

\section{References}

1. Östör AJK, Richards CA, Prevost AT, Speed CA, Hazleman BL. Diagnosis and relation to general health of shoulder disorders presenting to primary care.

Rheumatology.2005;44(6):800-805.doi:10.1093/rheumatology/keh598.

2. Minagawa H, Yamamoto N, Abe H, et al. Prevalence of symptomatic and asymptomatic rotator cuff tears in the general population: From massscreening in one village.

JOrthop.2013;10(1):8-12.doi:10.1016/j.jor.2013.01.008.

3. Tempelhof S, Rupp S, Seil R. Age-related prevalence of rotator cuff tears in asymptomatic shoulders. JShoulder Elb Surg.

1999;8(4):296-299. doi:10.1016/S1058-2746(99)90148-9.

4. Milgrom C, Schaffler M, Gilbert S, Van Holsbeeck M. Rotator-cuff changes in asymptomatic adults. The effect of age, hand dominance and gender. J Bone JtSurg-SerB.

1995;77(2):296-298. doi:10.1302/0301-620x.77b2.7706351.

5. Mather RC, Koenig L, Acevedo D, et al. The societal and economic value of rotator cuff repair. J Bone Jt Surg - Ser A. 2013;95(22):1993-2000. doi:10.2106/JBJS.L.01495.

6. Silverstein BA, Viikari-Juntura E, Fan ZJ, Bonauto DK, Bao S, Smith C. Natural course of nontraumatic rotator cuff tendinitis and shoulder symptoms in a working population. Scand J Work Environ Heal. 2006;32(2):99-108. doi:10.5271/sjweh.985.

7. Seida JC, LeBlanc C, Schouten JR, et al. Systematic review: Nonoperative and operative treatments for rotator cuff tears. Ann Intern Med. 2010;153(4):246-255. doi:10.7326/0003-4819-153-4-20100817000263.

8. Piper CC, Hughes AJ, Ma Y, Wang H, Neviaser AS. Operative versus nonoperative treatment for the management of full-thickness rotator cuff tears: a systematic review and meta-analysis. J Shoulder Elb Surg. 2018;27(3):572-576. doi:10.1016/j.jse.2017.09.032.

9. Lähteenmäki HE, Virolainen P, Hiltunen A, Heikkilä J, Nelimarkka OI. Results of early operative treatment of rotator cuff tears with acute symptoms. J Shoulder Elb Surg. 2006;15(2):148-153. doi:10.1016/j.jse.2005.07.006.

10. Gerber C, Fuchs B, Hodler J. The results of repair of massive tears of the rotator cuff. J Bone Jt Surg - Ser A. 2000;82(4):505-515. doi:10.2106/00004623-200004000-00006.

11. Dunn WR, Schackman BR, Walsh C, et al. Variation in orthopaedic surgeons' perceptions about the indications for rotator cuff surgery.J Bone Jt Surg-SerA.2005;87(9I):1978-1984. doi:10.2106/JBJS.D.02944.

12. Safran O, Schroeder J, Bloom R, Weil Y, Milgrom C. Natural history of nonoperatively treated symptomatic rotator cuff tears in patients 60 years old or younger. Am J Sports Med. 2011;39(4):710-714. doi:10.1177/0363546510393944.

13. MillettPJ, Horan MP, Maland KE, Hawkins RJ. Long-term survivorship and outcomes after surgical repair of full-thickness rotator cuff tears. J Shoulder Elb Surg. 2011;20(4):591-597. doi:10.1016/j.jse.2010.11.019.

14. Gladstone JN, Bishop JY, Lo IKY, Flatow EL. Fatty infiltration and atrophy of the rotator cuff do not improve after rotator cuff repair and correlate with poor functional outcome. Am J Sports Med. 2007;35(5):719-728. doi:10.1177/0363546506297539.

15. Inderhaug E, Kollevold KH, Kalsvik M, Hegna J, Solheim E. Preoperative NSAIDs, non-acute onset and long-standing symptoms predict inferior outcome at long-term follow-up after rotator cuff repair. Knee Surgery, Sport Traumatol Arthrosc. 2017;25(7):2067-2072. doi:10.1007/s00167-0153845-8.

16. Kuhn JE, Dunn WR, Sanders R, et al. Effectiveness of physical therapy in treating atraumatic full-thickness rotator cuff tears: A multicenter prospective cohort study. J Shoulder Elb Surg. 2013;22(10):1371-1379. doi:10.1016/j.jse.2013.01.026.

17. Karjalainen T V., Jain NB, Heikkinen J, Johnston R V., Page CM, Buchbinder $R$. Surgery for rotator cuff tears. Cochrane Database Syst Rev. 2019;2019(12). doi:10.1002/14651858.CD013502.

18. Downie BK, Miller BS. Treatment of rotator cufftears in older individuals: A systematic review. J Shoulder Elb Surg. 2012;21(9):1255-1261. doi:10.1016/j.jse.2011.11.019.

19. Huisstede BMA, Koes BW, Gebremariam L, Keijsers E, Verhaar JAN. Current evidence for effectiveness of interventions to treat rotator cuff tears. Man Ther.2011;16(3):217-230.doi:10.1016/j.math.2010.10.012.

20. Thorpe A, Hurworth M, O'Sullivan P, Mitchell T, Smith A. Rising trends in surgery for rotator cuff disease in Western Australia. ANZ J Surg. 2016;86(10):801-804. doi:10.1111/ans.13691.

21. Lin KM, Wang D, Dines JS. Injection Therapies for Rotator Cuff Disease. Orthop Clin North Am.

2018;49(2):231-239.doi:10.1016/j.ocl.2017.11.010.

22. Vrouva S, Batistaki C, Paraskevaidou E, et al. Comparative study of pain relief in two non-pharmacological treatments in patients with partial rotator 
cuff tears: A randomized trial. Anesthesiol Pain Med. 2019;9(2). doi:10.5812/aapm.88327.

23. Türkmen E, Analay Akbaba Y, Altun S. Effectiveness of video-based rehabilitation program on pain, functionality, and quality of life in the treatment of rotator cuff tears: A randomized controlled trial. J Hand Ther. Published online 2020.doi:10.1016/j.jht.2019.08.004.

24. HurdJL, Facile TR, Weiss J, et al. Safety and efficacy of treating symptomatic, partial-thickness rotator cuff tears with fresh, uncultured, unmodified, autologous adipose-derived regenerative cells (UA-ADRCs) isolated at the point of care: A prospective, randomized, controlled first-in-human pilot study. J Orthop Surg Res. 2020;15(1). doi:10.1186/s13018-020-016318 .

25. Lambers Heerspink FO, van Raay JJAM, Koorevaar RCT, et al. Comparing surgical repair with conservative treatment for degenerative rotator cuff tears: Arandomized controlled trial. J Shoulder Elb Surg. 2015;24(8):1274-1281.doi:10.1016/j.jse.2015.05.040.

26. Gialanella B, Comini L, Gaiani M, Olivares A, Scalvini S. Conservative treatment of rotator cuff tear in older patients: A role for the cycloergometer? A randomized study. Eur J Phys Rehabil Med. 2018;54(6):900-910. doi:10.23736/S1973-9087.18.05038-4.

27. Gialanella B, Bertolinelli M. Corticosteroids injection in rotator cufftears in elderly patient: Pain outcome prediction. Geriatr Gerontol Int. 2013;13(4):993-1001. doi:10.1111/ggi.12046.

28. Cai Y, Sun Z, Liao B, Song Z, Xiao T, Zhu P. Sodium Hyaluronate and Platelet-Rich Plasma for Partial-Thickness Rotator Cuff Tears. Med Sci SportsExerc.

2019;51(2):227-233. doi:10.1249/MSS.0000000000001781.

29. Akan O, Mete BD, Kocyigit H, Bayram KB, Yilmaz HE, Tosun A. Efficacy of ultrasound guided platelet-rich plasma in the repair of partial and fullthickness supraspinatus tears. Int J Clin Exp Med. 2019;12(9):1191811929.

30. Shams A, El-Sayed M, Gamal O, Ewes W. Subacromial injection of autologous platelet-rich plasma versus corticosteroid for the treatment of symptomatic partial rotator cuff tears. Eur J Orthop Surg Traumatol. 2016;26(8):837-842. doi:10.1007/s00590-016-1826-3.

31. Schwitzguebel AJ, Kolo FC, Tirefort J, et al. Efficacy of Platelet-Rich Plasma for the Treatment of Interstitial Supraspinatus Tears: A Double-Blinded, Randomized Controlled Trial. Am J Sports Med. 2019;47(8):1885-1892. doi:10.1177/0363546519851097.

32. Ranebo MC, Björnsson Hallgren HC, Holmgren T, Adolfsson LE. Surgery and physiotherapy were both successful in the treatment of small, acute, traumatic rotator cuff tears: a prospective randomized trial. J Shoulder Elb Surg. 2020;29(3):459-470. doi:10.1016/j.jse.2019.10.013.

33. Moosmayer S, Lund G, Seljom US, et al. At a 10-Year Follow-up, Tendon Repair Is Superior to Physiotherapy in the Treatment of Small and MediumSized Rotator Cuff Tears. J Bone Jt Surg - Am Vol. 2019;101(12):10501060. doi:10.2106/JBJS.18.01373.

34. Liu CT, Yang TF. Intra-substance steroid injection for full-thickness supraspinatus tendon rupture. BMC Musculoskelet Disord. 2019;20(1). doi:10.1186/s12891-019-2952-y.

35. Kukkonen J, Joukainen A, Lehtinen J, et al. Treatment of nontraumatic rotator cuff tears: A randomized controlled trial with two years of clinical and imaging follow-up. J Bone Jt Surg-Am Vol. 2014;97(21):1729-1737. doi:10.2106/JBJS.N.01051.
36. Krischak G, Gebhard F, Reichel $H$, et al. A prospective randomized controlled trial comparing occupational therapy with home-based exercises in conservative treatment of rotator cuff tears. J Shoulder Elb Surg. 2013;22(9):1173-1179. doi:10.1016/j.jse.2013.01.008.

37. Kim JH, Kim DJ, Lee HJ, Kim BK, Kim YS. Atelocollagen Injection Improves Tendon Integrity in Partial-Thickness Rotator Cuff Tears: A Prospective Comparative Study. Orthop J Sport Med. 2020;8(2). doi:10.1177/2325967120904012.

38. Rong Lim WS, Tjoen Lie DT, Mitra AK, Cheng Chang PC. What is the optimal surgical intervention for patients with frozen shoulder and a concomitant partial thickness rotator cuff tear? JSES Int. Published online 2020.doi:10.1016/j.jseint.2020.06.010.

39. Mak WK, Punn K, Lie DTT. Morphology, and a classification of massive cuff tears. Unpubl Data.Published online 2020.

40. Van Der Windt DAWM, Van Der Heijden GJMG, Scholten RJPM, Koes $B W$, Bouter LM. The efficacy of non-steroidal anti-inflammatory drugs (NSAIDS) for shoulder complaints. A systematic review. J Clin Epidemiol. 1995;48(5):691-704. doi:10.1016/0895-4356(94)00170-U.

41. Daniels S, Robbins J, West CR, Nemeth MA. Celecoxib in the treatment of primary dysmenorrhea: Results from two randomized, double-blind, activeand placebo-controlled, crossover studies. Clin Ther. 2009;31(6):11921208. doi:10.1016/j.clinthera.2009.06.003.

42. Chechik O, Dolkart O, Mozes G, Rak O, Alhajajra F, Maman E. Timing matters: NSAIDs interfere with the late proliferation stage of a repaired rotator cuff tendon healing in rats. Arch Orthop Trauma Surg. 2014;134(4):515-520.doi:10.1007/s00402-014-1928-5.

43. Cohen DB, Kawamura S, Ehteshami JR, Rodeo SA. Indomethacin and celecoxib impair rotator cuff tendon-to-bone healing. Am J Sports Med. 2006;34(3):362-369. doi:10.1177/0363546505280428.

44. Littlewood C, Ashton J, Chance-Larsen K, May S, Sturrock B. Exercise for rotator cuff tendinopathy: A systematic review. Physiotherapy. 2012;98(2):101-109. doi:10.1016/j.physio.2011.08.002.

45. Longo UG, Franceschi F, Berton A, Maffulli N, Droena V. Conservative treatment and rotator cufftear progression. Med Sport Sci. 2012;57:90-99. doi:10.1159/000328910.

46. Edwards P, Ebert J, Joss B, Bhabra G, Ackland T, Wang A. Exercise Rehabilitation in the Non-Operative Management of Rotator Cuff Tears: a Review of the Literature. Int J Sports Phys Ther. 2016;11(2):279-301. http://www.ncbi.nlm.nih.gov/pubmed/27104061\%0Ahttp://www.pub medcentral.nih.gov/articlerender.fcgi?artid=PMC4827371.

47. Goldberg BA, Nowinski RJ, Matsen FA. Outcome of nonoperative management of full-thickness rotator cuff tears. Clin Orthop Relat Res. 2001;(382):99-107.doi:10.1097/00003086-200101000-00015.

48. Kuhn JE. Exercise in the treatment of rotator cuff impingement: A systematic review and a synthesized evidence-based rehabilitation protocol. J Shoulder ElbSurg. 2009;18(1):138-160. doi:10.1016/j.jse.2008.06.004.

49. Moosmayer S, Tariq R, Stiris M, Smith HJ. The natural history of asymptomatic rotator cuff tears: A three-year follow-up of fifty cases. J Bone JtSurg-Ser A. 2013;95(14):1249-1255. doi:10.2106/JBJS.L.00185.

50. Abdul-Wahab TA, Betancourt JP, Hassan F, et al. Initial treatment of complete rotator cuff tear and transition to surgical treatment: Systematic review of the evidence. Muscles Ligaments Tendons J. 2016;6(1):35-47. doi:10.11138/mltj/2016.6.1.035.

51. Ryösä A, Laimi K, Äärimaa V, Lehtimäki K, Kukkonen J, Saltychev M. 
Surgery or conservative treatment for rotator cuff tear: a meta-analysis. Disabil Rehabil.

2017;39(14):1357-1363. doi:10.1080/09638288.2016.1198431.

52. Lin MT, Chiang CF, Wu CH, Huang YT, Tu YK, Wang TG. Comparative Effectiveness of Injection Therapies in Rotator Cuff Tendinopathy: A Systematic Review, Pairwise and Network Meta-analysis of Randomized Controlled Trials. Arch Phys Med Rehabil. 2019;100(2):336-349.e15. doi:10.1016/j.apmr.2018.06.028.

53. Koester MC, Dunn WR, Kuhn JE, Spindler KP. The efficacy of subacromial corticosteroid injection in the treatment of rotator cuff disease: A systematic review.

J Am Acad Orthop Surg. 2007;15(1):3-11. doi:10.5435/00124635200701000-00002.

54. Akgün K, Birtane M, Akarirmak Ü. Is local subacromial corticosteroid injection beneficial in subacromial impingement syndrome? Clin Rheumatol.2004;23(6):496-500. doi:10.1007/s10067-004-0930-7.

55. Wei AS, Callaci JJ, Juknelis D, et al. The effect of corticosteroid on collagen expression in injured rotator cuff tendon. J Bone Jt Surg - Ser A. 2006;88(6):1331-1338. doi:10.2106/JBJS.E.00806.
56. Yamaguchi T, Ochiai N, Sasaki YY, et al. Efficacy of hyaluronic acid or steroid injections for the treatment of a rat model of rotator cuffinjury. J Orthop Res. 2015;33(12):1861-1867. doi:10.1002/jor.22976.

57. Halici M, Karaoglu S, Canoz O, Kabak S, Baktir A. Sodium hyaluronate regulating angiogenesis during Achilles tendon healing. In: Knee Surgery, Sports Traumatology, Arthroscopy. Vol 12. Knee Surg Sports Traumatol Arthrosc; 2004:562-567. doi:10.1007/s00167-004-0536-2.

58. Osti L, Buda M, del Buono A, Osti R, Massari L. Clinical evidence in the treatment of rotator cuff tears with hyaluronic acid. Muscles Ligaments TendonsJ.2015;5(4):270-275. doi:10.11138/mltj/2015.5.4.270.

59. Nourissat G, Ornetti P, Berenbaum F, Sellam J, Richette P, Chevalier X. Does platelet-rich plasma deserve a role in the treatment of tendinopathy? Jt Bone Spine. 2015;82(4):230-234. doi:10.1016/j.jbspin.2015.02.004.

60. Mazzocca AD, McCarthy MBR, Chowaniec DM, et al. Platelet-rich plasma differs according to preparation method and human variability. J Bone Jt Surg-SerA. 2012;94(4):308-316.doi:10.2106/JBJS.K.00430.

61. Kim SJ, Kim EK, Song DH. Effects of bone marrow aspirate concentrate and platelet-rich plasma on patients with partial tear of the rotator cufftendon. $J$ Orthop Surg Res. 2018;13(1).doi:10.1186/s13018-017-0693-x.

Declaration of patient consent: The authors certify that they have obtained all appropriate patient consent forms. In the form, the patient has given his consent for his images and other clinical information to be reported in the Journal. The patient understands that his name and initials will not be published, and due efforts will be made to conceal his identity, but anonymity cannot be guaranteed.

\section{Conflict of interest: Nil Source of support: None}

\section{How to Cite this Article}

Sayampanathan AA, Tan MWP, Lie DTT | Role And Outcomes of Conservative Treatment in Management of Rotator Cuff Tears: A Systematic Review of Randomised Controlled Trial Asian Journal of Arthroscopy | January-June 2021; 6(1):39-47. 